\title{
Statistical analysis of bedslope, shape and fertigation timing to reduce nitrate loss in furrow fertigation
}

\author{
Parivash Raeisiyanfard ${ }^{\mathrm{a}}$, Azad Heidari ${ }^{\mathrm{b}}$, Sayyed-Hassan Tabatabaei ${ }^{\mathrm{c}}$ \\ a Graduated MSc, Water Engineering Department, Shahrekord University, Shahrekord, Shahrekord, Iran, \\ ${ }^{\mathrm{b}}$ Graduated Ph.D, Civil and Environmental Engineering Department, Michigan Technological University, Houghton, MI, USA \\ c Associate Professor, Water Engineering Department, Shahrekord University, Shahrekord, Shahrekord, Iran
}

\begin{abstract}
Improper use of chemicals in irrigation practices is one of the prime concerns for widespread surface and groundwater pollution in agricultural areas; thus, it is vital to improving chemical application through proper fertigation managements. This research focuses on the impact of shape, slope, and fertigation timing on furrow irrigation performance. The results demonstrated that the effects of furrow shape, bed slope, and timing of fertigation were statistically significant, and altering these parameters would change the absorbed nitrate and nitrate loss amounts.
\end{abstract}

Keywords: Furrow Irrigation; Fertigation; Nitrate loss; Variable bed slope; Variable cross-section

\section{Introduction}

Low irrigation water and fertilizer distribution efficiency make agriculture a major nonpoint source of water resources degradation. Application of nutrients, as well as pesticides via irrigation systems (i.e. fertigation), enables control on the distribution and balance of the applied chemicals. However, this complicated process requires an appropriate application to provide a proper and environmentally safe fertigation practice since several elements affect the distribution of chemicals through irrigation systems (Moreira Barradas et al. 2014; Sedaghatdoost et al. 2018).

Nitrogen application rates are usually much higher than of other nutrients, increasing the risk of nitrogen leaching in irrigated fields leading to water resources pollution and groundwater contamination (Mokari et al., 2019; Heidari et al., 2019). Furrow irrigation has the potential to increase fertilizer distribution efficiency in agricultural fields (Walker and Skogerboe, 1987; Sedaghatdoost and Ebrahimian, 2015; Simunek et al., 2016). Studies have revealed that change infurrow shapes resulted in the enhancement of fertigation performance. Among them, Soroush et al. (2012) found that meandering furrows would increase water and fertilizer application uniformity, whereas they would decrease advance time. Simunek et al. (2016) assessed the effects of different soil surface management strategies on root water and solute uptake along deep drainage and solute leaching. Their results indicated that the treatment which had plastic at the bottom of the furrow provided more water for transpiration; however, this treatment has more water lost due to deep percolation and evaporation.

Iran has a semi-arid climate that deals with water scarsity issues constantly and needs to implement high efficiency water resources management (Mokari Ghahroodi et al., 2015). Therefore, application of statistical and probabilistic methods for analysis of water resources in Iran has gained significant interest over the past few years (Araghinejad et al. 2018). The increasing population of Iran has and will continue polluting surface and groundwater and will put water resources under pressure (Javani et al. 2016; Sedaghatdoost et al. 2019). Changes in temperature and precipitation due to global warming (Fayaz et al. 2020) can exacerbate this situation. Considering that a major goal of Iranian national agricultural policy is providing food security through agriculture product independency that can be reached via higher water productivity (Soltani et al. 2015) and fertilizer use efficiency in mostly surface irrigated Iranian farms. This requires proper fertigation techniques to avoid polluting surface and groundwater resources. To achieve a higher uniformity, it might be necessary to use more than one slope, which for each case is dependent on infiltration parameters, Manning roughness coefficient, amount and rate of irrigation flow, and field geometry (González-Cebollada et al. 2016). Four different slopes were practiced on the furrow for this research. The overarching goal of this research was to study the availability of fertilizer at the root zone following a furrow fertigation event. The objectives of this study were to investigate the effects of field slope, furrow shape, and fertigation timing on nitrate concentration in the soil profile and fertilizer loss due to runoff. Moreover, to study the impact of alterations to fertigation timing, slope, and furrow shape on nitrate distribution. 


\section{Materials and Methods}

This study was done at an agricultural research field (32.21 N., 50.49 E.) in Shahrekord University, Iran. Soil texture at the study area was determined by the hydrometer method and USDA classification system. The salinity of the saturated extract (ECe) was measured in the lab based on the US Salinity Laboratory procedure. The furrow length and the longitudinal slopes were $100 \mathrm{~m}$ and 0.03 , respectively. Soil samples were collected using an auger from irrigated furrow beds in four soil layers $(0.0-0.15,0.15-0.30,0.30-0.45$, and $0.45-0.60 \mathrm{~m})$. Soil moisture and nitrate concentration were measured at the upstream, middle, and downstream of the experiment. Three adjacent furrows were used in which two outer furrows considered as buffers, and the middle furrow was used for data collection. The inflow of each furrow was $0.91 \mathrm{~L} / \mathrm{s}$ based on WinSRFR31 simulation of the farm conditions. Inflow and outflow rates were measured using trapezoidal WSC flume. Nitrate concentration was measured in surface water at the downstream of each furrow in addition to soils at three locations in the inlet, middle, and outlet of furrows after each fertigation event using the Bremner and Keeney (1965) method. The free-draining condition prevailed during the study period. The experimental field has a loam silt soil with no vegetation. The physical and chemical properties of the soil are shown in Table 1.

Table 1: Soil physical properties and irrigation water quality at the experimental site

\begin{tabular}{|c|c|c|c|c|c|c|c|c|}
\hline & \multicolumn{8}{|c|}{ Parameter } \\
\hline & $\mathrm{pH}$ & $\mathrm{EC}(\mathrm{dS} / \mathrm{m})$ & Soil texture & Clay (\%) & Sand (\%) & Silt (\%) & $\rho_{b}\left(\mathrm{gr} / \mathrm{cm}^{3}\right)$ & $\mathrm{N}-\mathrm{NO}^{-3}(\mathrm{mg} / \mathrm{L})$ \\
\hline \multirow[t]{3}{*}{ Soil } & 7.1 & 0.19 & Loam-silt & 21.5 & 28.2 & 50.3 & 1.15 & 4.55 \\
\hline & \multicolumn{8}{|c|}{ Parameter } \\
\hline & $\mathrm{N}-\mathrm{NO}^{-3}(\mathrm{mg} / \mathrm{L})$ & $\mathrm{PH}$ & $\mathrm{EC}(\mathrm{dS} / \mathrm{m})$ & TDS (mg/L) & TSS (mg/L) & \multicolumn{3}{|c|}{ SAR (mmol/lit) $)^{0.5}$} \\
\hline Water & 2.61 & 7.54 & 0.3 & 38 & 0 & \multicolumn{3}{|c|}{0.13} \\
\hline
\end{tabular}

The experiment was conducted in Randomized Complete Blocks (RCB) design with a split-plot arrangement and three replications. In order to study the role of field slope, furrow shape, and fertigation timing on fertigation performance (advance and recession time, nitrate concentration in the soil profile, fertilizer loss due to runoff), seven treatments were conducted (Table. 2). Control treatment had a 3\% steady slope with fixed furrow geometry. In the control treatment, injecting fertilizer was done in the whole irrigation event.

Table. 2. Summary of seven treatments applied in the study

\begin{tabular}{ll}
\hline Treatment & Abbreviation \\
\hline Steady slope, full-time fertigation & CTRL \\
Concave slope, full-time fertigation & VS-T \\
Concave slope, first half time fertigation & VS- FH \\
Concave slope, second halftime fertigation & VS- SH \\
Changing cross-section, full-time fertigation & VCS-T \\
Changing cross-section, first half time fertigation & VCS-FH \\
Changing cross-section, second halftime fertigation & VCS-SH \\
\hline
\end{tabular}

For investigating the effect of field slope on fertigation performance, furrows were divided into four parts $(0-25,25-50$, 50-75, and 75-100 m intervals). The first two parts of the furrow had steeper slopes compared to the two other parts so 
that the water will move faster at the beginning and gets slower as it reaches the middle of the field (Fig. 1). The slopes were chosen this way, so the average slope of the field slope is kept at $3 \%$.

The efficiency of the fertigation system can be evaluated by the measurement of fertilizer runoff and leaching. Fertilizer leaching can be estimated by measuring deep percolation and nitrate amount in the soil solution below the root zone (Mailhol et al., 2001). Distribution uniformity of low half $\left(\mathrm{DU}_{\mathrm{LH}}\right)$ and a low quarter $\left(\mathrm{DU}_{\mathrm{LQ}}\right)$ were used as indicators of distribution uniformity (Merriam and Keller 1978):

$$
\begin{gathered}
D U_{L Q}=\frac{d_{L Q}}{D} \\
D U_{L H}=\frac{d_{L H}}{D}
\end{gathered}
$$

Where $d_{L Q}$ and $d_{L H}$ are the average of the lower half and lower quarter of infiltrated water depth or fertilizer mass, respectively, and $\mathrm{D}$ is the average of infiltrated depth of water or fertilizer mass.

The irrigation duration was 100 minutes, which was a result of infiltration experimentation and advance time. One kilogram of urea fertilizer (46\%) was dissolved with 100 liters of water in a fertilizing tank and was used for Fertigation (table 1). The amount of water and nitrate, in percentage that percolate beyond the root zone considered as water and nitrate deep-percolation fraction $(\mathrm{DPw})$.

\section{Results and discussion}

\subsection{Nitrate concentration comparison in upstream of the furrows}

Nitrate concentrations were determined by taking samples at different depths, and the values were reported in $\mathrm{mg} / \mathrm{kg}$. The results of the statistical analysis for nitrate concentration at upstream, center, and downstream of the furrows are presented in table 3 .

Table 3: Results from Variance Analysis for nitrate concentration in different depths at upstream, central and downstream of

\begin{tabular}{|c|c|c|c|c|c|c|c|c|c|c|c|c|c|}
\hline & \multirow[t]{3}{*}{$\begin{array}{l}\text { Degree of } \\
\text { freedom }\end{array}$} & \multicolumn{4}{|c|}{$\begin{array}{c}\text { Depths at the upstream of } \\
\text { furrows }\end{array}$} & \multicolumn{4}{|c|}{ Depths at the center of furrows } & \multicolumn{4}{|c|}{$\begin{array}{l}\text { Depths at the downstream of } \\
\text { furrows }\end{array}$} \\
\hline & & $15 \mathrm{~cm}$ & $30 \mathrm{~cm}$ & $45 \mathrm{~cm}$ & 60 & 15 & $30 \mathrm{~cm}$ & $45 \mathrm{~cm}$ & $60 \mathrm{~cm}$ & $15 \mathrm{~cm}$ & $30 \mathrm{~cm}$ & $45 \mathrm{~cm}$ & $60 \mathrm{~cm}$ \\
\hline & & & & & $\mathrm{cm}$ & $\mathrm{cm}$ & & & & & & & \\
\hline Block & 2 & $\begin{array}{l}1154 \\
\text { ns }\end{array}$ & $713^{\mathrm{ns}}$ & $\begin{array}{l}1605 \\
\text { ns }\end{array}$ & $26^{\mathrm{ns}}$ & $\begin{array}{l}2782 \\
\mathrm{~ns}\end{array}$ & $\begin{array}{l}2129 \\
\mathrm{~ns}\end{array}$ & $244^{\mathrm{ns}}$ & $\begin{array}{l}1415 \\
\text { ns }\end{array}$ & $127 \mathrm{~ns}$ & $119^{\mathrm{ns}}$ & $26^{\mathrm{ns}}$ & $148^{\mathrm{ns}}$ \\
\hline Treatment & 6 & $6363^{* *}$ & $6281^{* *}$ & $6679^{* *}$ & 4882 & $4677^{*}$ & $6519^{* *}$ & $7708^{* *}$ & $8071^{* *}$ & $4808^{* *}$ & $6074^{* *}$ & $6726^{* *}$ & $7660^{* *}$ \\
\hline Error & 12 & 775 & 507 & 936 & 5 & 1250 & 1164 & 368 & 498 & 169 & 117 & 57 & 149 \\
\hline
\end{tabular}
the furrows

Note: $\mathrm{ns}=$ not significant

*: Significance at $5 \%$ probability levels.

$* *$ : Significance at $1 \%$ probability levels.

The VCS-SH and VS-SH treatments, which were second-half fertigation with various cross-sections and various slope, respectively, had the highest amounts of nitrate at all depths. The next highest was the VS-T and VCS-T treatments, which are full-time fertigation concave slope and fulltime fertigation various cross-section, respectively. These results are consistent with the results of Hou et al. (2007), Abbasi et al. (2003), Playan and Faci (1996), who reported that the highest fertilizer efficiency occurred when fertigation was applied in the second half and the whole period of irrigation. Results showed that the furrow's shape and slope had a similar impact on fertigation at lower depth, and the fertigation timing had a significant effect on treatment's efficiency at deeper depths.

The impacts of slope and cross-section on nitrate concentration in different treatments were similar for $45 \mathrm{~cm}$ depths. In contrast, fertigation timing was more significant at deeper soils. For the various cross-section treatments, the highest 
nitrate amount of $153 \mathrm{mg} / \mathrm{kg}$ belonged to the second half fertigation compared to $102 \mathrm{mg} / \mathrm{kg}$ that belongs to full-time irrigation and only $53 \mathrm{mg} / \mathrm{kg}$ in first halftime irrigation. This finding can be significant based on the root depth of a crop that is going to be fertigated. Furthermore, field and fertilizer should be prepared and practiced in a way that the highest possible amount of nitrate will be available at the root depth of the crop.

These results indicate that shape, the slope of the furrow, and the timing of irrigation were sensitive parameters in fertigation efficiency. At all depth, the second half fertigation treatments had the highest amounts of nitrate concentration. Then, there were full-time fertigation treatments that were consistent with the previous research. According to Jaynes et al. (1992), the spatial distribution of nitrate in surface irrigation was dependent on design and management variables. In this research, the control treatment had the lowest amount of nitrate, which indicates that efficiency can increase with appropriate practices of slope and shape of the furrows.

\subsection{Nitrate concentration comparison in the center of the furrows}

At this section of the furrow, the highest nitrate concentration belonged to the VCS-SH and VCS-T treatments, respectively (table3, figure 1). Similar to the previous comparisons, the second half and full-time fertigation treatments performed better by having higher nitrate concentrations at different depths, which indicated the importance of fertigation timing. Thus, the fertigation timing was found to be remarkably impactful on soil's nitrate absorption. Finding the highest fertigation efficiency to belong to the second half fertigation is similar to other research from Hou et al. (2007), Abbasi et al. (2003), Playan and Faci (1997). Furthermore, they have addressed the full-time fertigation as a high-efficiency attempt, which the same occurred at this research, especially in the second part of the furrow (VCS-T treatment).

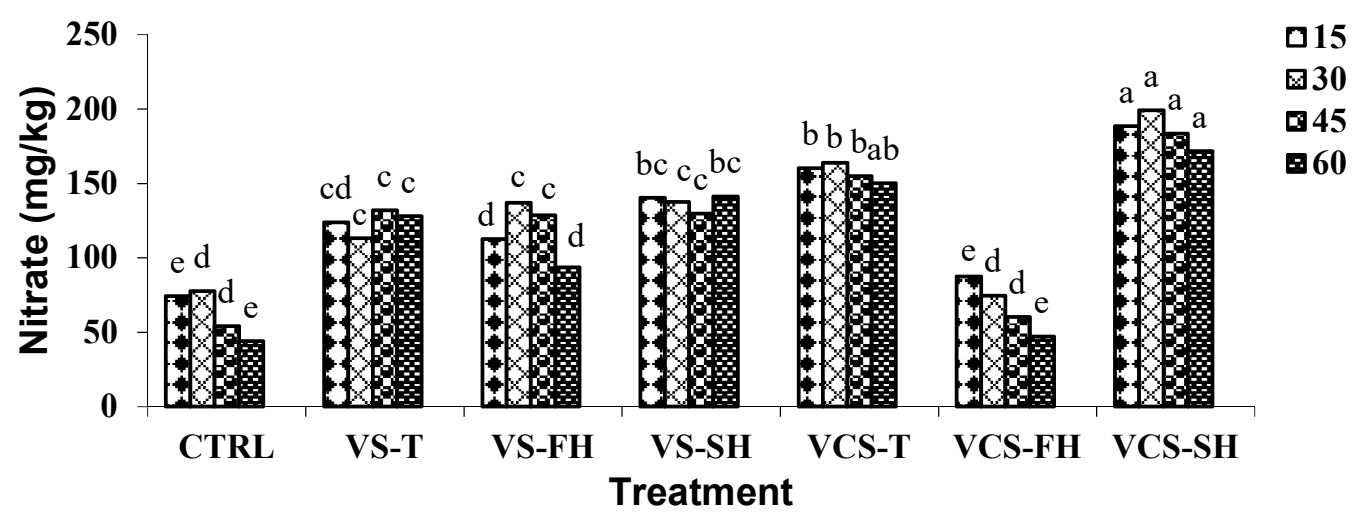

Fig 1: Nitrate concentration in different depths of 15 to $60 \mathrm{~cm}$ at the center of the furrows

One major difference at this part of the furrow was that the various cross-section treatments showed better performance compared to various slope in both fulltime and second half fertigation. The VCS-SH treatments had notable higher average amounts of nitrate at different depths $(185.8 \mathrm{mg} / \mathrm{kg})$ compared to VS-SH, with an average of $137 \mathrm{mg} / \mathrm{kg}$. These findings showed that cross-section was a more impactful parameter in the middle of the furrows. This can be explained as the cross-section gets smaller, higher nitrate is absorbed by furrow (as a reason for increased depth, that affects nitrate transfer and absorption, according to Mailhol et al. (2001 and 2007).

The VCS-FH treatment, along with CTRL treatment, belonged to the same statistical classes and had had a very poor performance by having the lowest nitrate amount. Again the poorest performance of the CTRL treatment demonstrated the positive effects that shape and slope of the furrow can have on nitrate absorption. But, it should be noted that slope and shape, along with appropriate fertigation timing, could make a big difference and provide the highest performance. Otherwise, the time and effort for preparing the field might go to waste, as shown here by VCS-FH treatment.

\subsection{Nitrate concentration comparison at the downstream of the furrows}

Results from table 3 showed that there was a significant difference among treatments; however, there was no difference between the replications. The highest nitrate concentration belonged to the VCS-SH and VCS-T treatments, respectively, which indicated the simultaneous impact of timing and cross-section at this part of the furrow. For the concave slope treatments (VS), the nitrate amounts were similar, and there was no significant difference between the treatments, which 
puts them in the same statistical class. Furthermore, it implied that fertigation timing was not a sensitive parameter at the downstream of the concave sloped field. Comparing these results indicated that at this part of the furrow (downstream), cross-section had a bigger impact. This can be explained as the shape of the furrow is a physical parameter, and solute transport in the soil is dependent on different parameters, including the physical, chemical, and biological properties of the soil. At the end portion of the furrow, more nitrate was absorbed in VCS treatments because, at this point, the crosssection is smaller, and the moisture and flow depth is increased.

The second half of an irrigation event has a better moisture distribution; thus, when the fertigation starts at this time, nitrate is absorbed by the soil more easily, which improves the fertigation efficiency. At deeper depths, the impact of fertigation timing becomes notable. It seems that in deeper depth, the fertigation timing is the most effective parameter. One possible explanation could be nitrate has a tendency to move downward in the soil profile. The impact of fertigation timing also confirms results from other researchers' results. Hou et al. (2007), Abbasi et al. (2003), Playan and Faci (1997). Similar to previous sections of the furrow, the lowest nitrate concentration was reported for the CTRL treatment, which was similar to VCS-FH treatments.

\subsection{The total amount of nitrate in the soil and total nitrate loss}

Figure 2 shows the amount of nitrate concentration in all the treatments. Results (figure 2) show that the highest nitrate concentration belonged to the VCS-SH and VCS-T treatments. These findings again indicate the impact of fertigation timing and cross-section. Although the VCS-T was fertigated the whole duration, it had high amounts of nitrate at the studied depths. This proves that cross-section can be even more important than fertigation timing in some cases considering nitrate absorption.

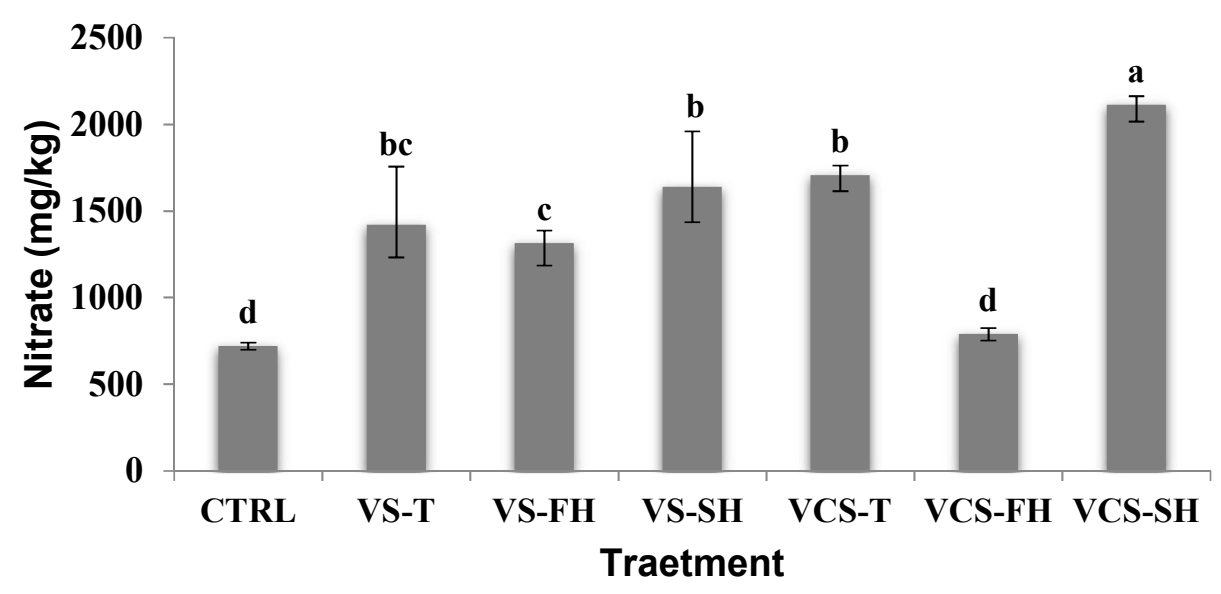

Fig 2: Nitrate concentration in all sections of the furrows

Figure 3 shows the amount of nitrate loss for different treatments at three-time steps of the first half of the irrigation, second half, and after the full irrigation period. Results show the highest nitrate loss was observed for the VS-FH and VS$\mathrm{T}$ treatments, respectively, which shows that the highest nitrate loss occurred in the concave slope treatments. Also, CTRL treatment suffered a high nitrate loss. On the other hand, the lowest nitrate loss belonged to VCS-SH treatment. Considering the amount of loss during the second half of the irrigation, Results shows that the concave slope furrows had higher amounts of nitrate loss. The statistical analysis for the nitrate loss, considering the full period of irrigation, showed that the highest nitrate loss occurred at the VS-FH treatment. In general, the various cross-section treatments had better results, meaning they lost less nitrate comparing to other treatments. Furthermore, the second half fertigation treatments lost smaller amounts of nitrate, showing that they have a better nitrate efficiency. Li and Zhang (2003) demonstrated that fertigation managements lead to a remarkable decline of nitrate loss from leaching and runoff. So, proper management of narrowing cross-section along the furrow and second half fertigation should be applied to prevent extreme nitrate loss. Hou et al. (2007) stated that the lowest nitrate loss occurs when fertigation is in the second half, which follows this research's results. 


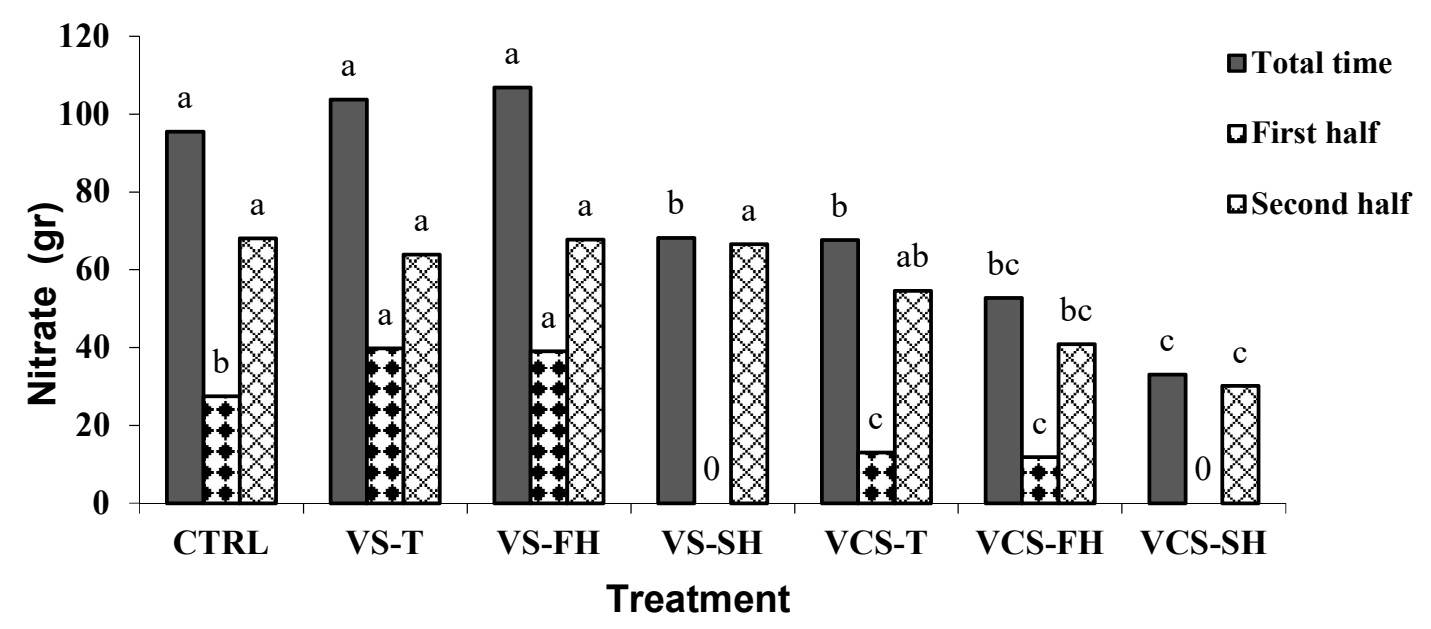

Fig 3: Nitrate loss comparison in first, second and the whole irrigation time

It can be concluded that with proper design and management of surface irrigation, the fertigation efficiency could improve significantly. One proper management attempt is to make changes in the furrow cross-section and furrow slope so that the fertigation efficiency increases. These results follow researches of and Di and Cameron (2002). They found that lower nitrate losses were achieved as a result of simultaneous managing of fertilizer and irrigation water by making proper management decisions on fertigation timing.

\section{Conclusion}

The slope and cross-section of the furrows were changed to increase the fertigation efficiency during furrow irrigation. The goals were to improve the nitrate availability in soil and root zone and to decrease nitrate leaching to prevent environmental and groundwater pollution. Furthermore, three different time lengths of the first half, second half, and fulltime fertigation were examined. These variables resulted in a total of seven treatments of various slope and cross-section and irrigation timing with three repetitions. The measurements were conducted in different depths of $15,30,45$, and $60 \mathrm{~cm}$ and at the upstream, center, and downstream of the furrows. The results of the experiment show that the various furrow cross-sections with second-half fertigation (VCS-SH) treatment had the best nitrate distribution uniformity and the highest amount of absorbed nitrate $(175.95 \mathrm{mg} / \mathrm{kg})$ and lowest amounts of nitrate loss $(33.11 \mathrm{mg} / \mathrm{kg})$. The furrow cross-section reduction that occurs leads to efficiency and nitrate absorption improvement, especially at the downstream of the furrow more nitrate was absorbed in VCS treatments because at this point the cross-section is smaller and the moisture and flow depth is increased. The second half of an irrigation event has a better moisture distribution; thus, when the fertigation started at this time, nitrate was absorbed by the soil more easily, which improved the fertigation efficiency. The concave slope furrow with second-half fertigation (VS-SH) treatment showed satisfactory performance in terms of nitrate distribution and absorption $(136.63 \mathrm{mg} / \mathrm{kg})$. The steep slope at the beginning of the furrow helps to improve water and nitrate distribution uniformity.

\section{Acknowledgment}

The authors would like to thank the Water Engineering Department of Shahrekord University for supporting this research and appreciate the cooperation of students of the University of Tehran for this research project.

\section{References}

Abbasi, F., Feyen, J., Roth, R. L., Sheedy, M., \& van Genuchten, M. T. (2003). Water flow and solute transport in furrow-irrigated fields. Irrigation Science, 22(2), 57-65.

Araghinejad, S., Fayaz, N., \& Hosseini-Moghari, S. M. (2018). Development of a hybrid data driven model for hydrological estimation. Water Resources Management, 32(11), 3737-3750. 
Bremner, J. M., \& Keeney, D. R. (1965). Steam distillation methods for determination of ammonium, nitrate and nitrite. Analytica chimica acta, 32, 485-495.

Di, H. J., \& Cameron, K. C. (2002). Nitrate leaching in temperate agroecosystems: sources, factors and mitigating strategies. Nutrient cycling in agroecosystems, 64(3), 237-256.

Fayaz, N., Condon, L.E. \& Chandler, D.G. Evaluating the Sensitivity of Projected Reservoir Reliability to the Choice of Climate Projection: A Case Study of Bull Run Watershed, Portland, Oregon. Water Resour Manage (2020). https://doi.org/10.1007/s1 1269-020-02542-3.

González-Cebollada, C., Moret-Fernández, D., Buil-Moure, I., \& Martínez-Chueca, V. (2016). Optimization of field topography in surface irrigation. Journal of Irrigation and Drainage Engineering, 142(8), 04016026.

Ghahroodi, E. M., Noory, H., \& Liaghat, A. M. (2015). Performance evaluation study and hydrologic and productive analysis of irrigation systems at the Qazvin irrigation network (Iran). Agricultural Water Management, 148, $189-195$. Heidari, A., Mayer, A. and Watkins Jr, D., (2019). Hydrologic impacts and trade-offs associated with forest-based bioenergy development practices in a snow-dominated watershed, Wisconsin, USA. Journal of Hydrology, 574, pp.421-429.

Hou, Z., Li, P., Li, B., Gong, J., \& Wang, Y. (2007). Effects of fertigation scheme on N uptake and N use efficiency in cotton. Plant and Soil, 290(1-2), 115-126.

Javani, H., Hassanoghli, A., Liaghat, A., \& Heidari, A. (2016). A study of columns to reduce mineral and biological pollutants during recharge operation by treated municipal wastewater. Desalination and Water Treatment, 57(32), 14919-14928.

Jaynes, D. B., Rice, R. C., \& Hunsaker, D. J. (1992). Solute transport during chemigation of a level basin. Transactions of the ASAE, 35(6), 1809-1815.

Li, J., Zhang, J., \& Ren, L. (2003). Water and nitrogen distribution as affected by fertigation of ammonium nitrate from a point source. Irrigation Science, 22(1), 19-30.

Mailhol, J. C., Crevoisier, D., \& Triki, K. (2007). Impact of water application conditions on nitrogen leaching under furrow irrigation: Experimental and modelling approaches. Agricultural Water Management, 87(3), 275-284.

Mailhol, J., Ruelle, P., \& Nemeth, I. (2001). Impact of fertilisation practices on nitrogen leaching under irrigation. Irrigation science, 20(3), 139-147.

Merriam, J. L., \& Keller, J. (1978). Farm irrigation system evaluation: A guide for management. Farm irrigation system evaluation: a guide for management.

Moreira Barradas, J. M., Abdelfattah, A., Matula, S., \& Dolezal, F. (2015). Effect of fertigation on soil salinization and aggregate stability. Journal of Irrigation and Drainage Engineering, 141(4), 05014010.

Mokari, E., Shukla, M. K., Šimůnek, J., \& Fernandez, J. L. (2019). Numerical Modeling of Nitrate in a FloodIrrigated Pecan Orchard. Soil Science Society of America Journal, 83(3), 555-564.

Playán, E., Faci, J. M., \& Serreta, A. (1996). Characterizing microtopographical effects on level-basin irrigation performance. Agricultural water management, 29(2), 129-145. 
Sedaghatdoost, A., \& Ebrahimian, H. (2015). Calibration of infiltration, roughness and longitudinal dispersivity coefficients in furrow fertigation using inverse modelling with a genetic algorithm. Biosystems Engineering, 136, 129139.

Sedaghatdoost, A., Ebrahimian, H., \& Liaghat, A. (2018). Estimating soil hydraulic and solute transport parameters in subsurface drainage systems using an inverse modelling approach. Irrigation and drainage, 67, 82-90.

Sedaghatdoost, A., Ebrahimian, H., \& Liaghat, A. (2019). An Inverse Modeling Approach to Calibrate Parameters for a Drainage Model with Two Optimization Algorithms on Homogeneous/Heterogeneous Soil. Water resources management, 33(4), 1383-1395.

Šimůnek, J., Bristow, K. L., Helalia, S. A., \& Siyal, A. A. (2016). The effect of different fertigation strategies and furrow surface treatments on plant water and nitrogen use. Irrigation Science, 34(1), 53-69.

Soltani, M., Liaghat, A. M., Sotoodehnia, A., Heidari, A., \& Kamali, B. (2015). Conjunctive effects of supplemental irrigation and planting date on rainfed lentil in Qazvin Plain, Iran. Journal of Irrigation and Drainage Engineering, 141(12), 05015005.

Soroush, F., Mostafazadeh-Fard, B., Mousavi, S. F., \& Abbasi, F. (2012). Solute distribution uniformity and fertilizer losses under meandering and standard furrow irrigation methods. Australian Journal of Crop Science, 6(5), 884. Walker, W. R., \& Skogerboe, G. V. (1987). Surface irrigation. Theory and practice. Prentice-Hall. 